\title{
Using Information Technology to Promote Thinking
}

\author{
Maree A. Skillen \\ Arden Anglican School, Sydney, Australia \\ docree@bigpond.com
}

\begin{abstract}
The goal of this research study was to investigate the implementation and evaluation of a variety of digital media and web-based solutions and their effect and contribution on the learning environment in relation to the promotion of students' thinking skills. In particular, the objectives of the study included: an assessment of the educational value of a variety of multimedia and webbased solutions using different evaluation approaches; an investigation of the contribution of digital media in the development of an inquiry-oriented learning environment; an examination of the enhancement of students' skills in the use of digital media, and the examination of an inquiry-oriented multimedia and web-based solution while the students, the computer and the teacher interacted to create a social constructivist learning environment. In particular, the research described in this study involved an investigation of the implementation of digital media - utilising Macromedia multimedia and web-based solutions for school project work - in a Year 9/10 Information and Software Technology (IST) elective course: Internet and Web Design. It concentrated on the subsequent assessment and impact that the software had on creating an inquirybased situation to promote higher-order thinking skills among students completing multimedia projects for publication on the World Wide Web within a secondary classroom.
\end{abstract}

Keywords: Technology, thinking, interactive multimedia, constructivism.

\section{Introduction}

\section{"Technology is really a way of thinking".}

(Australian Academy of Technological Sciences and Engineering, 2004, p.1)

This study emerged from interest in and experience with the use of digital media in the secondary Information and Communication Technology (ICT) classroom. The research focused particularly on how technology is used as a tool in the teaching and learning process. Special attention was paid to the theory of constructivism and the emphasis that a constructivist perspective has on students' evolving knowledge; that is, the critical role that social negotiation plays in helping students interpret their experiences, and the promotion of thinking skills when using technology. Much of the literature suggests that the primary responsibility of the instructional expert is to 
create and maintain the constructivist notion of a collaborative problem-solving environment (Dick, 1992; Crick, 1994). Hackbarth (1996) supports this view by noting that constructivism has become a dominant force in society. The essential principle of this theory is that each person assembles the bits and pieces of experience in ways that are unique. This study examines how students use technology to assist with their personal construction of knowledge, along with the development of thinking skills utilised to complete the practical tasks. Drawing upon prior conceptions and feelings, people actively interact with their surroundings in an ongoing effort to make the diversity of experiences all sensible and coherent. The essential challenge of constructivism has been in its shifting the locus of control over learning from the teacher to the student. Educational technologists, with their roots in behavioural psychology, have long sought to design programs in such a way that students would be enticed to achieve pre-specified objectives. Constructivists have claimed that this violates both what is now known about the nature of learning (situated, interactive), and about the nature of knowledge (perspectival, conventional, tentative, evolutionary). They have maintained that objectives should be negotiated with students based on their felt needs; that planned activities should emerge from within the contexts of their lived worlds; that students should collaborate with peers in the social construction of personally significant meaning, and that evaluation should be a personalised, ongoing, shared analysis of progress.

The influences of constructivism on educational technology can be seen in many areas. Models of communication can portray the process as interactive, with the message as much determined by the selective perception of the recipient as by the style of the author. Mediated programs are seen now more in terms of providing students with opportunities to expand their range of interests, knowledge and/or experiences. Interactive multimedia (IMM) presentations are seen to provide students with insights into the thinking of experts, and the "scaffolding" needed to enable their own uniquely coloured construction of disciplined knowledge. Romiszowski (1992), defines interactive instruction as a process in which the learner is involved in overtly responding to material by making selections or giving answers to questions. Interactivity in the instructional process operates by setting tasks for the learner to deal with, but its value and its nature are best described by the "depth of processing" or the quality of thinking that is demanded from the student. IMM comes in various forms and has the potential to enhance education, though there has been little opportunity for educators to gain experience in how to effectively use and critically evaluate this new media (Wiburg, 1995). IMM products have the capacity to shift the locus of 'ownership' and 'control' in learning. Learning has traditionally been 'controlled' by the teacher, the instructor or the computer-based instructional system. The end-users of IMM courseware can be empowered to own and control their own learning (Latchem, Williamson \& Henderson-Lancett, 1993). IMM is a particularly effective medium for providing such search-through problem environments. Another central issue in IMM instructional design is the design philosophy of increasing learner control over the 'what' and the 'how' of learning. Latchem et.al. (1993) highlight that it is important for designers of IMM products to provide the end-user with "a handful of simple ways to travel from one object to another (by keyword, object search, text type or random choice) which lets people create many paths through a rich territory without getting lost or hitting a dead-end". 
The three issues in optimising IMM design are linking, meaning making connections and allowing alternative ways for the attainment of information; human interface, meaning the point of interconnection between a computer and the person using it and involves ease-of-use, depth of structure (that is, will the product be useful to advanced/expert users?) and navigational features (for example, buttons, graphic hot spots) and content, meaning information made available by an electronic medium or product. Each of these issues relate to the practical project work observed during this case study in which students engaged as they planned and developed the digital media into an accessible and user-friendly website.

\section{Aims of the Study}

The goals of this study involved the amalgamation of two aims, namely, an investigation into the evaluation and implementation of digital media which includes multimedia and web-based solutions, and an examination of their effect on and contribution to the learning environment in relation to the promotion of thinking skills among students. These may be expressed in terms of the following objectives:

1. To evaluate the educational value of a variety of digital media.

2. To investigate the contribution of digital media in the development of an inquiry-oriented learning environment.

3. To enhance students' skills in the use of digital media.

4. To develop, implement and evaluate the use of inquiry-based learning with digital media through a social constructivist environment.

\section{Research Questions}

In order to provide a focus for these objectives, the following research questions were formulated:

1. Can digital media contribute to and enhance inquiry-based learning within the secondary classroom?

2. What is the impact of using digital media on students' abilities in the classroom learning environment?

3. How does digital media enable the student to develop higher-order thinking skills?

4. How can constructivist strategies be promoted through the development and use of digital media?

The implications of this study for teaching and learning via a digital media approach to promote thinking skills within students were considered in light of the results.

\section{Key Concepts in the Study}

The concepts discussed in this section were identified as being important in establishing the theoretical framework for this study. 
- Thinking skills

- Critical and creative thinking

- Higher-order thinking (HOT) skills

- Information and Communication Technology (ICT)

- Interactive Multimedia (IMM)

- Constructivism and social constructivism

- Project-based multimedia learning and digital media

Research has shown that today's generation of student is comfortable using computers and digital media as forms of communication (Scherer, 2005-2006). As educators, we are seeking to support this contention by seeking new ways to integrate technology across the curriculum and to provide engaging, relevant projects for students that build valuable digital skills. The Year 9/10 IST class observed aimed to engage students actively in project work that was related to real-world experiences and that allowed them to utilise different types of thinking skills.

Simkins, Cole, Tavalin and Means (2002) examined the effect of increasing student learning through multimedia projects. They defined project-based multimedia learning as "a method of teaching in which students acquire new knowledge and skills in the course of designing, planning, and producing a multimedia product (p. 2)". Students involved in this research study developed multimedia products that were technology-based and utilised digital media to create websites. Digital media refers to any form of information that has been "digitised" or "converted" for storage or use on a computer (Crothers, 1997). It encompasses digital audio, digital video, the World Wide Web (Internet) and other technologies that can be used to create and distribute digital "content" (Wales \& Sanger, 2001b).

Constructivism refers to a learning theory that views learning as a process where the learner actively constructs or builds new ideas or concepts based upon current and past knowledge (Duffy \& Jonassen, 1992). This perspective is beneficial to students in terms of social processes and the change in an individual's understanding as well as, promoting a student's free exploration within a given framework or structure. As educators, we need to recognise that education is centred on themes and concepts and the connections between them, rather than isolated information. Students learn best when they gain knowledge through exploration and active learning. The use of hands on materials and the encouragement of students to think and explain their reasoning instead of memorising and reciting facts is an example of constructivism in action.

Krause et. al. (2003, p. 157) assert that constructivism takes several different forms, two of which include "psychological constructivism" and "social constructivism". While both are identified as sharing a focus on individuals constructing their own learning, it is clear that each also has a different emphasis: one on the individual, the other on the social context. Social constructivism draws heavily on Vygotsky's belief that social processes are integral to learning (Krause et. al., 2003, p. 157). This approach rejects the view that the locus of knowledge lies within the individual. Rather, the social constructivist view is that social interaction shapes cognitive development and is an essential component of the learning process (Cobb \& Yackel, 1996; Prawat, 1996). In addition, Doolittle (1999) refers to social constructivism as knowledge which is the result of social interaction and language 
usage, and thus is a shared, rather than an individual, experience. He continues by referring to it as being a type of constructivism that is concerned more with meaning rather than structure. In the classroom, observers see a combination of the various forms of constructivism at work as students focus on the learning and teaching process. In the class observed for this research study, students were able to select their own topic area of interest for the minor and major projects. They were required to find information and design layouts, then to construct a final product that clearly conveyed information about their topic. The role of social and cultural factors in shaping learning experiences was emphasised during each lesson and was clearly evident through examples such as: student-student and student-teacher engagement and interactions, the use and increase of language by students with one another, the variety of selected topics that indicated an individuals interest and involvement in the wider community.

\section{Definitions of Key Terms in the Study}

There are several terms used throughout the study that were identified as being important and need to be defined in order to establish a common understanding.

- Web authoring and web authoring tools

- Computer Assisted Learning (CAL)

- Inquiry-based learning activities

- Tools for inquiry

- Effective learning

- Effective teaching

- Assessment: formative, summative, authentic

\section{Research Methodology}

\subsection{The Case Study Approach}

The fieldwork for the research carried out in this study was implemented using a case study approach. Rather than using large samples and following rigid protocols to examine a limited number of variables, the case study method was selected as it allowed me to establish an in-depth longitudinal examination, over a period of 18 months, of set focus areas within the secondary ICT classroom. In particular, I was able to investigate authentic student and teacher activity. Whilst the experience was unpredictable and complex, it provided a systematic way for me to examine what was happening, collect data in different forms, analyse the information and then report the results.

\subsection{The Sample}

For this study, one secondary ICT class was selected from a school located in the Sydney metropolitan area. Participating students were enrolled in the Year 9/10 IST elective course: Internet and Web Design. The area of Computing Studies was 
selected for the study because of the requirements from the New South Wales Board of Studies that students be familiar with the use of database design, digital media, Internet and website development and multimedia programs. The teacher involved in the study became my collaborative colleague to discuss the class, issues that arose and progress being made.

\subsection{The Software}

For this study, students used digital media with an emphasis on the Macromedia multimedia and web-based solutions suite. In particular, the structure of the Year 9/10 IST elective course encouraged students to develop knowledge and technical skills in the use of Flash, Fireworks and Dreamweaver. Initial projects were developed using Microsoft Notepad to enable students to develop skills and an appreciation for HTML code prior to using a customised package for the development of higher-end project work that demanded more variations in the completed product.

\subsection{Instrumentation}

The primary quantitative data gathering tool used for this study was the 'What is Happening in this Class (WIHIC)' classroom environment instrument (Aldridge, Fraser, \& Huang, 1999). The WIHIC was used to examine how the teacher and students perceived the classroom environment to be with relation to the use of technology. It was used to gather data on both the preferred and actual perceptions of the staff and students involved. The WIHIC instrument was administered to both the teacher and students with a five-month interval between the examination of each group's preferred and actual perceptions. A computer background survey was implemented with the class to obtain information from the fifteen students about their access to computer technology, use of computers both at home and at school, interest and personal assessment of the ease with which they use technology, and regularity of use of the Internet and multimedia programs.

\subsection{Data Collection}

The 18 month long study was conducted to investigate whether the use of digital media can facilitate higher-order thinking within the learning of secondary ICT students. As part of this investigation, a 20-week intensive classroom-based field observation was implemented and involved both qualitative and quantitative approaches. Johnson and Onwuegbuzie (2004) refer to the combination of the methods represented by these two forms of data gathering as a mixed methodology approach. During the observation period, 30 lessons of 75 minutes duration were formally visited to view students engaged with the classroom technology. Specifically, the data collection methods implemented included: a pre-questionnaire; field notes (descriptive; observations); informal student and teacher discussions; formal student and teacher interviews; student work samples; computer-based student answer files, and a post-questionnaire. Staff and students responded to a classroom environment inventory prior to using the digital media and again after three months. The qualitative methods involved in the study included observations and extensive field note recording. For the purposes of this study, I assumed the role of a 
participant-observer (Maor \& Taylor, 1995) in the classroom of one secondary ICT teacher. This role enabled me to monitor selected students' application to task, and the thinking they utilised and/or displayed through the completion of the set activities. Field notes were recorded to document observations of both the teacher and students during each lesson. These notes recorded the learning taking place, whole-class discussions, individual interactions, student-student interactions and teacher-student interactions. During the second half of the school semester, classroom observations and field notes were further supported by access to entries made at the end of each lesson by students in an online diary of classwork.

\subsection{Quality Controls}

Johnson and Onwuegbuzie (2004, p. 22) discuss the mixed methods research process with reference to Onwuegbuzie and Teddlie's (2003) seven-stage conceptualisation of the mixed methods data analysis process which involves data reduction, data display, data transformation, data correlation, data consolidation, data comparison, and data integration. The research methodology was broadly ethnographic, and used data collection techniques of participant-observation, interviewing and verification techniques of triangulation and respondent validation (Jaworski, 1998). As Jaworski (1998, p. 112) describes, the methodology of this research study was conducted from a researcher as instrument position, meaning that an important instrument in both data collection and analysis was the researcher. During this study, I was aware of the need for quality controls, particularly for the qualitative research approaches implemented. These controls refer to the recommendations of Guba and Lincoln (1989) and other factors considered by Denzin and Lincoln (1994).

\subsection{Data Analysis}

During the implementation phase of this study, analysis of the data was an ongoing process. This process involved the review of detailed field notes taken during observations of the selected class and students, transcribed interviews by students and teaching and executive staff, the review of online diary entries and the analysis of student work samples that were in both electronic and paper-based format. It was necessary to examine the data and to triangulate the various data sources gathered.

\section{Significance of the Study}

It was anticipated that this research would contribute to future investigations related to the teaching and learning of secondary students within technology-orientated classrooms. In particular, the research study is significant for a number of reasons, as discussed briefly below.

First, it is likely to provide new information about the extent to which students can develop higher-level thinking skills using web authoring tools that utilise digital media. Second, it is likely to provide information related to the contribution that these tools have on changing the learning environment to be inquiry-oriented. This would support the research conducted by Coulter (2000) who investigated the role that technology has played in the provision for and enhancement of an inquiry 
environment. The third area to which the study is likely to contribute is in facilitating comparisons with the work of Cooper and Maor (1998) who utilised multimedia to create a student-centred learning environment to examine the implementation of computer software whilst encouraging its use with students' in order to observe the presence of higher-level thinking skills. Cooper and Maor (1998) based some of their research investigations on the work of Grabinger (1996, p. 688) who posed questions including:

- How can we design machines to help people learn and think?

- Does this mean machines need to replicate human processes or that machines support processes?

- Can we use machines to help make the learning processes visible and more accessible?

Further comparative information can be gathered and considered from the studies conducted by Maor and Taylor (1995) who examined student achievements related to higher-level thinking skills, and the investigation of the mediation role of teachers' epistemologies in high school computerised classes. In addition, studies by Maor and Fraser (1996) concentrating on how the use of a classroom environment instrument can monitor perceptions in evaluating inquiry-based CAL are relevant to the investigations conducted within this study. These investigations may provide comparative results related to the analysis of a technology contentbased classroom, its environment and the actual and preferred perceptions of the students and teachers.

The study is likely to contribute to investigations related to constructivism within the secondary ICT classroom. Jonassen (2002) and a number of researchers have conducted various investigations in relation to technology. In particular, he has examined constructivist perspectives for learning with technology, computers as mindtools for engaging learners as critical thinkers, and using computers as cognitive tools. The findings from this study will refer to the literature produced from these studies and highlight particular findings of significance that support and add to the identified areas of investigation. Denning, Fisher, Higgins, Loveless and Tweats (2003, p. 31) state that there "remains a daunting gap between that which is most often measured as a contribution to 'standards' and the acquisition and use of higherorder and metacognitive skills that may also go hand in hand with the use of ICT in the classroom". They refer to McGuiness (1999) who provided an informed and concise account of the present state of our engagement and understanding of thinking skills. It is hoped that this research study can look at the 'gap' referred to and work towards a better understanding of the impact that ICT can have on learning and thinking. Reeves (1992, p. 185) believes that research in the area of multimedia, learning and the links between them "has never been more important". He indicated that multimedia does not automatically guarantee higher-order learning and refers to Hawking (1988, p. 186) who states that "the difficulty of researching how people learn via IMM can be compared to the difficulty involved in measuring the development of black holes in space". The research conducted in this study aimed to examine some of these concepts. The study also aimed to contribute to an area that has been clearly identified as one that demands further investigation. 


\section{References}

Australian Academy of Technological Sciences and Engineering (ATSE). In: Technology is really a way of thinking. Parkville, Australia (2004)

Aldridge, J., Fraser, B., Huang, T.: Investigating classroom environments in Taiwan and Australia with multiple research methods. Journal of Educational Research 93, 48-57 (1999)

Cobb, P., Yackel, E.: Constructivist, emergent, and sociocultural perspectives in the context of developmental research. Educational Psychologist 31, 175-190 (1996)

Cooper, M., Maor, D.: Mathematics, multimedia and higher level thinking skills. In: Proceedings Western Australian Institute of Educational Research Forum 1998 (1998), http: / / education.curtin.edu.au/waier/forums/1998/cooper.html

Coulter, B.: Technology for learning: how does technology support inquiry? Connect (a publication of Synergy Learning) 13(4) (March/April 2000)

Crick, F.: The astonishing hypothesis: the scientific search for the soul. Simon and Schuster, New York (1994)

Crothers, R.: Digital by design: an introduction to digital media. Access Education, Greenwood (1997)

Denning, T., Fisher, T., Higgins, C., Loveless, A., Tweats, R.: Thinking skills and ICT use in the classroom? Paper presented at the IFIP Working Groups 3.1 and 3.3 Working Conference: ICT and the Teacher of the Future, The University of Melbourne, Australia (January 2003)

Denzin, N.K., Lincoln, Y.S. (eds.): Handbook of qualitative research. Sage Publications, London (1994)

Dick, W.: An instructional designer's view of constructivism. In: Duffy, T., Jonassen, D. (eds.) Constructivism and the technology of instruction: A conversation. Erlbaum, Hillsdale (1992)

Doolittle, P.: Constructivism and Online Education. Fort Wayne, IN: Online Conference on Teaching Online in Higher Education (October 1999),

http: / /www. cdtl. nus. edu.sg/brief/V6n1/sec2 . html

(retrieved January 22, 2006)

Duffy, T.M., Jonassen, D.H.: Constructivism and the technology of instruction: a conversation. Erlbaum, Hillsdale (1992)

Grabinger, R.S.: In: Jonassen, D.H. (ed.) Handbook of Research for Educational Communications and Technology, pp. 665-692. Simon and Schuster Macmillan, New York (1996)

Guba, E.G., Lincoln, Y.S.: Fourth generation evaluation. Sage Publications, Newbury Park (1989)

Hackbarth, S.: The Educational Technology Handbook - A Comprehensive Guide: Process and Products for Learning, Englewood Cliffs, New Jersey (1996)

Hawking, W.H.: A brief history of time: from the big bang to black holes. Vantage, New York (1988); Reeves, T.C.: Research Foundations for Interactive Multimedia. In: Proceedings of the International Interactive Multimedia Symposium, Perth, Western Australia, pp. 177190 (January 1992)

Jaworski, B.: The centrality of the researcher: rigor in a constructivist inquiry into Mathematics teaching (Chapter 8). In: Teppo, A.R. (ed.) Qualitative Research Methods in Mathematics Education. JRME Monograph No. 9, pp. 112-127. NCTM, Reston (1998)

Johnson, R.B., Onwuegbuzie, A.J.: Mixed methods research: a research paradigm whose time has come. Educational Researcher 33(7), 14-26 (2004) 
Jonassen, D.H.: Computers as mindtools in schools: engaging critical thinking. Merrill, Upper Saddle River (2002)

Krause, K., Bochner, S., Duchesne, S.: Educational psychology for learning and teaching. Thomson, Victoria (2003)

Latchem, C., Williamson, J., Henderson-Lancett, L. (eds.): Interactive Multimedia: Practice and Promise. Kogan Page, London (1993)

Maor, D., Fraser, B.J.: Use of classroom environment perceptions in evaluating inquiry-based computer-assisted learning. International Journal of Science Education 18, 401-421 (1996)

Maor, D., Taylor, P.C.: Teacher epistemology and scientific inquiry in computerised classroom environments. Journal of Research in Science Teaching 32, 839-854 (1995)

McGuiness, C.: From thinking skills to thinking classrooms. Research Brief No. 115. DfES, London (1999)

New South Wales Board of Studies, Information and Software Technology Years 7-10 syllabus documentation (NSW Board of Studies, Sydney) (June 2003)

Onwuegbuzie, A.J., Teddlie, C.: A framework for analyzing data in mixed methods research. In: Tashakkori, A., Teddlie, C. (eds.) Handbook of Mixed Methods in Social and Behavioral Research, pp. 351-383. Sage, Thousand Oaks (2003)

Prawat, R.S.: Learning community, commitment and school reform. Journal of Curriculum Studies 28(1), 91-110 (1996)

Reeves, T.C.: Research Foundations for Interactive Multimedia. In: Proceedings of the International Interactive Multimedia Symposium, Perth, Western Australia, pp. 177-190 (January 1992)

Romiszowski, A.J.: Developing interactive multimedia courseware and networks. Paper Presented at the Meeting of the International Interactive Multimedia Symposium, Western Australia, Perth (1992)

Simkins, M., Cole, K., Tavalin, F., Means, B.: Increasing student learning through multimedia projects. ASCD, Alexandria (2002),

http: / /www.ascd.org/publications/books/102112/chapter1.html (retrieved November 26, 2004)

Wales, J., Sanger, L.: Wikipedia: the free encyclopedia - Multimedia (January 2001c), http: //en.wikipedia.org/wiki/Multimedia (retrieved November 16, 2005)

Wiburg, K.: Becoming critical users of multimedia. The Computing Teacher 22, 59-61 (1995) 